\title{
Yersinia enterocolitica: Prevalence, virulence, and antimicrobial resistance from retail and processed meat in Egypt
}

\author{
Gamal Younis, Mona Mady and Amal Awad \\ Department of Bacteriology, Mycology and Immunology, Faculty of Veterinary Medicine, Mansoura University, Mansoura, \\ 35516, Egypt. \\ Corresponding author: Amal Awad, e-mail: amalabdo@mans.edu.eg \\ Co-authors: GY: gamalyounis_2006@yahoo.com, MM: mona.angel221@yahoo.com \\ Received: 09-03-2019, Accepted: 12-06-2019, Published online: 21-07-2019
}

doi: 10.14202/vetworld.2019.1078-1084 How to cite this article: Younis G, Mady M, Awad A (2019) Yersinia enterocolitica: Prevalence, virulence, and antimicrobial resistance from retail and processed meat in Egypt, Veterinary World, 12(7): 1078-1084.

\begin{abstract}
Background and Aim: The objectives of this study were to investigate the prevalence of Yersinia enterocolitica in retail chicken meat, ground and processed beef meat, determine their virulence-associated genes, antimicrobial susceptibility pattern, molecular detection of extended-spectrum $\beta$-lactamases, and their capability of biofilm formation in vitro.

Materials and Methods: A total of 210 samples (120 retail chicken meat, 30 ground beef, 30 beef burger, and 30 sausage samples) were collected from different retail chicken outlets and markets located at Mansoura city between December 2016 and April 2017. Meat samples were examined bacteriologically for the existence of $Y$. enterocolitica; bacterial colonies that displayed positive biochemical properties were subjected to polymerase chain reaction targeting 16 rRNA gene. $Y$. enterocolitica isolates were tested for their susceptibility to six antimicrobial agents using disk diffusion method. Uniplex PCR was used for screening $Y$. enterocolitica isolates for the presence of two virulence chromosome-associated genes (ail and $y s t$ ), and $\beta$-lactamases ( $b l a_{\mathrm{TEM}}$ and $\left.b l a_{\mathrm{SHV}}\right)$. The capability of $Y$. enterocolitica to form biofilms was detected by tube method.

Results: Thirty $Y$. enterocolitica isolates (14.29\%) were recovered including 19 (15.83\%) isolates from chicken meat, $3(10 \%)$ from ground beef, $5(16.67 \%)$ from beef burger, and $3(10 \%)$ from sausage samples. Regarding ail gene, it was detected in 6.67\% (2/30), while yst gene detected in 20\% (6/30) Y. enterocolitica isolates. About 80\%, 70\%, 63.33\%, and $50 \%$ of $Y$. enterocolitica isolates were sensitive to ciprofloxacin, gentamicin, cefotaxime, and streptomycin, respectively, while $83.33 \%$ of $Y$. enterocolitica isolates were resistant to both ampicillin and cephalothin. Interestingly, 21 (70\%) isolates had the capability of biofilms formation in vitro. Among the multidrug-resistant (MDR) strains, a significant difference $(p<0.05)$ was found between MDR and biofilm formation. However, biofilm formation was correlated with the resistance of the isolates to $\beta$-lactam antimicrobials and the presence of $\beta$-lactam-resistant genes.
\end{abstract}

Conclusion: The presence of $Y$. enterocolitica in chicken meat, ground and processed beef meat represents a significant health risk for meat consumers, which reflects the contamination of slaughterhouses and processing operations, therefore, strict hygienic measures should be applied to minimize carcasses contamination.

Keywords: antimicrobial susceptibility, biofilm formation, virulence genes, Yersinia enterocolitica.

\section{Introduction}

Foodborne diseases are prevalent and growing public health concern worldwide [1]. In Egypt, there is currently a lack of information on the occurrence of foodborne diseases including Yersiniosis. Yersiniosis is a gastrointestinal infection caused by Yersinia enterocolitica which is considered the most prevalent gastrointestinal infection after campylobacteriosis and salmonellosis in the industrial countries [2]. Y. enterocolitica is a psychotropic waterborne and foodborne enteropathogen that has the capability to grow at refrigeration temperatures [3]. Contaminated meat, chicken, milk, and cheese with $Y$. enterocolitica cause

Copyright: Younis, et al. Open Access. This article is distributed under the terms of the Creative Commons Attribution 4.0 International License (http://creativecommons.org/licenses/by/4.0/), which permits unrestricted use, distribution, and reproduction in any medium, provided you give appropriate credit to the original author(s) and the source, provide a link to the Creative Commons license, and indicate if changes were made. The Creative Commons Public Domain Dedication waiver (http://creativecommons.org/ publicdomain/zero/1.0/) applies to the data made available in this article, unless otherwise stated. a significant health risk for consumers, especially in young children and infants [4,5].

$Y$. enterocolitica has been isolated from different sources including animals, food, and environment. Pigs are considered the main reservoir for human pathogenic strains of $Y$. enterocolitica, so pigs and pig products are the main sources for human infection [5]. However, poultry meat has been also implicated in $Y$. enterocolitica infections [6] as birds are commonly subclinical carriers of the organism [7].

The most common clinical symptoms of $Y$. enterocolitica infections are enteritis, enterocolitis, acute diarrhea, fever, abdominal pain, mesenteric lymphadenitis, and pseudoappendicitis [8]. It has strong ability for extraintestinal spreading under defined host conditions causing extraintestinal manifestations, including wide range of clinical symptoms [9].

$Y$. enterocolitica strains have the ability to cause the disease due to the presence of different virulence factors located in the chromosome or carried on a $70 \mathrm{~kb}$ virulence plasmid (pYV), which is only 
detected in virulent strains [10]. Two chromosomal virulent-associated genes (ail and yst) were included in our analysis. The ail gene (adhesion invasion locus) encodes a surface factor that enhances epithelial cell penetration, is involved in adhesion and invasion, and is found only among pathogenic strains [11]. The $y s t$ gene encodes enterotoxin is frequently detected in diarrheagenic biotype 1A strains [12].

Antimicrobial treatment is not necessary for treating $Y$. enterocolitica in immunocompetent hosts because most gastrointestinal infections are self-limiting. However, systemic, extraintestinal, and invasive infections in immunocompromised patients with increased risk for developing bacteremia or septicemia require special attention and antibiotic therapy since the mortality rate in these cases can be as high as $50 \%$ [10]. Ciprofloxacin, ceftriaxone, and cefotaxime have been used successfully for complicated infection treatments such as liver abscess, endocarditis, and septicemia [13].

Bacterial biofilm is a community of microorganisms surrounded by a self-produced matrix consisting of an extracellular polymeric substance of polysaccharides, lipids, proteins, and nucleic acids [14]. Biofilm formation protects bacterial cells from antibacterial agents, phagocytes, bacteriophages, and antibodies. In food industry, biofilms increase the resistance of bacteria to many physical and chemical factors which represent a food safety concern. Accordingly, the process of biofilm formation represents a method of protection for microbial growth allows bacterial cells to survive and grow in several adverse environments. In addition, the formation of biofilms may result in chronic infection due to the resistant of pathogens to both host immunity and antibiotic treatment [15].

Therefore, this study was designed (1) to investigate the prevalence rate of $Y$. enterocolitica in chickens meat, ground and processed beef meat samples collected from Mansoura, Egypt, with the determination of its associated chromosomal virulence genes (ail and $y s t)$; (2) to determine the antimicrobial susceptibility patterns, $\beta$-lactam resistance genes, and biofilm formation; and (3) to ascertain if there is a relationship between biofilm formation and multidrug-resistant (MDR) isolates.

\section{Materials and Methods}

\section{Ethical approval}

There was no need for ethical approval in this study because no live animals were involved. Meat samples were collected from retail outlets and various supermarkets.

\section{Samples collection}

A total of 210 samples were examined in this study, including 120 retail chicken meat samples, 30 ground beef samples, and 60 processed meat samples (30 beef burger and 30 sausage). Meat samples were chosen randomly from retail outlets and various supermarkets in Mansoura city, Egypt, from December 2016 to April 2017. The collected samples (approximately $50 \mathrm{~g}$ each) were kept separately in a sterile plastic bag, labeled, and delivered to the laboratory for bacteriological examinations in an ice container.

\section{Isolation and identification of $Y$. enterocolitica isolates}

About $25 \mathrm{~g}$ of each sample was homogenized in $225 \mathrm{ml}$ of peptone, sorbitol, and bile salts broth (PSB; Difco, Heidelberg, Germany) and homogenized in a Stomacher for $2 \mathrm{~min}$ at high speed. Homogenized samples were incubated at $25^{\circ} \mathrm{C}$ for $72 \mathrm{~h}$. Then, a loopful of the enriched samples was streaked into Cefsulodin-Irgasan-Novobiocin agar medium plates (Oxoid) and incubated for $24 \mathrm{~h}$ at $30^{\circ} \mathrm{C}$ under aerobic conditions. Colonies with typical red bull's eye-like colonies (small, with a red center and translucent rim) were purified on the surface of tryptic soy agar plates (Oxoid) and then stored at $4{ }^{\circ} \mathrm{C}$ for further examination. Preliminary identification of $Y$. enterocolitica isolates depended on the colony morphological criteria by Gram's stain and biochemically subjected to the following biochemical tests: catalase, oxidase, urease production, Simmons citrate, triple sugar iron, and sugar fermentation [16]. Furthermore, a 16S rRNAbased polymerase chain reaction (PCR) technique was used for $Y$. enterocolitica confirmation using the primers and the conditions listed in Table-1 [17-20].

\section{Molecular detection of $\beta$-lactam resistance genes and virulence-associated genes}

The cell lysates from $Y$. enterocolitica isolates were obtained by boiling [7] to be used as DNA templates. Confirmed Y. enterocolitica were screened for

Table-1: Oligonucleotide primers sequences used in this study.

\begin{tabular}{|c|c|c|c|c|c|}
\hline Target Gene & Primer & Sequence & Annealing & Amplicons size & References \\
\hline \multirow[t]{2}{*}{ Y. enterocolitica $16 \mathrm{~S}$ rRNA } & $Y 1$ & AATACCGCATAACGTCTTCG & 60 & $330 \mathrm{bp}$ & [17] \\
\hline & Y2 & СТTCTTCTGCGAGTAACGTC & & & \\
\hline \multirow[t]{2}{*}{ ail } & ail- $F$ & TAATGTGTACGCTGCGAG & 55 & $351 \mathrm{bp}$ & {$[18]$} \\
\hline & ail- $R$ & GACGTCTTACTTGCACTG & & & \\
\hline \multirow[t]{2}{*}{ yst } & $\operatorname{Pr} 2 a$ & AATGCTGTCTTCATTTGGAGC & 55 & 145 bp & \\
\hline & $\operatorname{Pr} 2 c$ & АTCCСАATСАСТАСТGАСТTC & & & \\
\hline \multirow[t]{2}{*}{$b / a_{\mathrm{TEM}}$} & TEM-F & АTTCTTGAAGACGAAAGGGC & 60 & 1150 & [19] \\
\hline & $T E M-R$ & ACGCTCAGTGGAACGAAAAC & & & \\
\hline \multirow{2}{*}{$b l a_{\mathrm{SHV}}$} & $S H V-F$ & CACTCAAGGATGTATTGTG & 50 & 885 & {$[20]$} \\
\hline & $S H V-R$ & TTAGCGTTGCCAGTGCTCG & & & \\
\hline
\end{tabular}

$Y$. enterocolitica $=$ Yersinia enterocolitica 
the presence of two virulence chromosome-associated genes, including adhesion invasion locus gene (ail) encoded a surface factor that enhanced epithelial cell penetration and the heat-stable enterotoxin encoded $y s t$ using the primers and PCR conditions listed in Table-1 [17-20] according to the referred authors. Furthermore, $Y$. enterocolitica isolates were also screened for the presence of $\beta$-lactam resistance genes including $b l a_{\mathrm{TEM}}$ and $b l a_{\mathrm{SHV}}$. PCRs were performed with Applied Biosystem, 2720 Thermal Cycler (USA) in a total volume of $25 \mu \mathrm{L}$ consisted of $12.5 \mu \mathrm{L}$ of $2 \times$ PCR master mix (Promega, Madison, USA), $1 \mu \mathrm{L}$ of each primer (Metabion, Germany), $4.5 \mu \mathrm{L}$ PCRgrade water, and $6 \mu \mathrm{L}$ DNA template. The amplicons were separated in agarose gel 1.5\% (Lonza Rockland, ME, USA) in TBE buffer stained with ethidium bromide. Gels were photographed by Gel Doc (Cleaver Scientific Ltd., USA).

\section{Antimicrobial susceptibility testing}

Antimicrobial susceptibility of $Y$. enterocolitica isolates was determined against six different antimicrobials belonged to different antimicrobial classes using Kirby-Bauer disk diffusion method on MuellerHinton agar (Oxoid) plates following the Clinical and Laboratory Standards Institute guidelines [21]. The following antimicrobial disks (Oxoid) used were cefotaxime $(30 \mu \mathrm{g})$, gentamicin $(10 \mu \mathrm{g})$, streptomycin $(10 \mu \mathrm{g})$, ciprofloxacin $(5 \mu \mathrm{g})$, ampicillin $(10 \mu \mathrm{g})$, and cephalothin $(30 \mu \mathrm{g})$.

\section{Biofilm formation}

$Y$. enterocolitica isolates were examined for its capability of biofilms production using tube method. In brief, a loopful of each isolate has been inoculated separately in $5 \mathrm{ml}$ trypticase soy broth (TSB; Becton Dickinson, Sparks, USA). The inoculated tubes were incubated at $28^{\circ} \mathrm{C}$ for $24 \mathrm{~h}$, and then, $1 \mathrm{ml}$ from the incubated broth was transferred into another sterilized $4 \mathrm{ml} \mathrm{TSB}$ and incubated at $28^{\circ} \mathrm{C}$ for $24 \mathrm{~h}$. Uninoculated tube of TSB was used as a control. After incubation, the previously inoculated broth was discarded carefully, and the tubes were stained with $1 \%$ crystal violet for $15 \mathrm{~min}$; excess stain was discarded and washed with deionized water. The stained tubes were left to dry in an inverted position and photographed to determine biofilm formation [22].

\section{Statistical analysis}

The variation in the prevalence of virulence genes, beta-lactam-resistant genes, and biofilm formation was calculated by Chi-square test. A statistically significant difference did exist if $p<0.05$. Pearson's correlation was used to study the correlation between all studied phenotypic and genotypic features of $Y$. enterocolitica isolates using the R program Ver. 324 (Package: corrplot). For creating the correlation matrix, the numbers " 1 " and " 0 " were assigned for the presence and absence of the corresponding genes, respectively.

\section{Results and Discussion}

$Y$. enterocolitica is one of the leading foodborne infections, which also could become a significant health risk for consumers. However, it is not considered among the most frequent food-related pathogens such as Salmonella and Campylobacter; it is of great concern in terms of food safety as it can survive and grow at refrigeration temperature [23]. In this study, a total of 210 meat samples were examined for the presence of $Y$. enterocolitica using the conventional cultural methods and molecular characterization mentioned. All recovered $Y$. enterocolitica isolates were genetically verified as $Y$. enterocolitica strains by molecular detection of $16 \mathrm{~S}$ rRNA gene. Among the total examined samples, 30 isolates $(14.29 \%)$ were identified to be $Y$. enterocolitica (Table-2). The prevalence of $Y$. enterocolitica in chicken meat was $15.83 \%$ $(19 / 120)$. In agreement with our findings, Shabana et al. [24] could isolate $Y$. enterocolitica in a prevalence rate of $17.5 \%$ from raw chicken meat in Egypt while Momtaz et al. [25] found that $18.33 \%(132 / 720)$ chicken meat samples were positive for $Y$. enterocolitica in Iran. Comparing to the obtained results, Anju et al. [6] could not identify $Y$. enterocolitica from chicken meat while Sirghani et al. [26] recorded a higher percentage (30\%) from chicken meat in Iran.

The prevalence rate of $Y$. enterocolitica recovered from ground beef samples was 10\% (3/30) which was lower than that detected by Karib et al. [27], who found that $15 \%(3 / 20)$ of the ground beef samples were contaminated with $Y$. enterocolitica. The prevalence rate of $Y$. enterocolitica in beef burger samples was $16.67 \%(5 / 30)$, which was higher than that obtained by Nortjé et al. [28], while the prevalence rate of $Y$. enterocolitica from sausage samples was $10 \%(3 / 30)$ which was higher than that reported by Nortjé et al. [28]. Interestingly, a higher prevalence $(16.67 \%)$ of $Y$. enterocolitica contamination was recorded from beef burger.

Table-2: Isolation rate of $Y$. enterocolitica from the examined meats samples.

\begin{tabular}{lccc}
\hline Types of samples & $\begin{array}{c}\text { Number of examined } \\
\text { samples }\end{array}$ & $\begin{array}{c}\text { Number of positive } \\
\text { samples }\end{array}$ & $\begin{array}{c}\text { Percentage of positive } \\
\text { samples }\end{array}$ \\
\hline Chicken meat & 120 & 19 & 15.83 \\
Ground beef & 30 & 3 & 10 \\
Beef burger & 30 & 5 & 16.67 \\
Sausage & 30 & 3 & 10 \\
Total & 210 & 30 & 14.29 \\
\hline
\end{tabular}

Y. enterocolitica $=$ Yersinia enterocolitica 
$Y$. enterocolitica that contains virulence factor only has the capability to induce disease [29]. Virulence genes in $Y$. enterocolitica located either on chromosome or on a plasmid named pYV. The most significant virulence genes located on chromosome include ail, inv, and yst. Detection of ail gene is a key factor to distinguish pathogenic and non-pathogenic $Y$. enterocolitica [30]. In this study, $Y$. enterocolitica isolates were examined for the presence of two chromosomal genes because plasmid pYV is easily lost depending on various factors [31]. The ail gene is a type of protein responsible for adhesion and invasion [11], while yst is an enterotoxin, commonly found in diarrheagenic biotype 1A strains [12]. The obtained results from this study reveal the presence of ail in $6.67 \%(2 / 30)$ of the tested isolates, while yst was carried by six strains $(20 \%)$. The obtained results from the present study were in accordance with Peng et al. [32] and lower than that described by Sacchini et al. [33], who could detect ail and yst from all tested Y. enterocolitica isolates, while Bhagat and Virdi [34] could not identify both genes in their study. The pathogenicity of $Y$. enterocolitica associated closely with ail gene, biotypes, and serotypes [35]. The diversity in the pathogenicity of $Y$. enterocolitica isolates may be depended on the geographical area of isolation. By testing the correlation between the presence of the two virulence genes used, we found a strong positive correlation between them (yst and ail: 0.56).

Antimicrobial resistance among $Y$. enterocolitica isolates was tested against ampicillin (AMP), cephalothin (CF), ciprofloxacin (CIP), gentamicin (GN), cefotaxime (CTX), and streptomycin (S). Regarding $\beta$-lactam resistance, $83.33 \%(25 / 30)$ of the examined isolates showed resistance to both ampicillin and cephalothin. The tested strains revealed intermediate resistant against streptomycin $(50 \% ; 15 / 30)$ and a lower resistance was revealed by cefotaxime $(36.67 \%$; $11 / 30)$ followed by gentamicin $(30 \% ; 9 / 30)$ and ciprofloxacin $(20 \% ; 6 / 30)$ as shown in Table-3. Sixteen resistance patterns were detected; the most common pattern was S, CF, AMP represented by eight strains followed by $\mathrm{CF}$ and AMP displayed by five strains. MDR to $\geq 3$ of the antimicrobial classes tested was detected in $7(23.33 \%)$ of $Y$. enterocolitica isolates; among them, the most common profile was CTX, S, $\mathrm{CF}$, and AMP.

Antimicrobial resistance possesses by Gramnegative bacteria including $Y$. enterocolitica which represents a significant public health problem worldwide. In this study, the antimicrobial resistance of $Y$. enterocolitica isolates was higher in comparison with other studies; it was noticed that $Y$. enterocolitica showed higher rate of ampicillin and cephalothin resistance $(83.33 \%$ each) which is in agreement with the previous studies [1,33,36,37]; the high percentage of resistance to $\beta$-lactam antimicrobial may be attributed to the ability of $Y$. enterocolitica to produce $\beta$-lactamases, which contribute to ampicillin and cephalothin resistance [38]. MDR was detected in $23.33 \%(7 / 30)$ of $Y$. enterocolitica isolates, but none of the examined isolates was resistance to all of the tested antimicrobial agents. However, the isolates show high susceptibility to ciprofloxacin, gentamicin, cefotaxime, and streptomycin. The antimicrobial resistance pattern of the isolated $Y$. enterocolitica strains is described in Table-4. By testing the correlation between phenotypic and genotypic antimicrobial susceptibility, we found a positive correlation between the presence of $b l a_{\text {TEM }}$ gene with the phenotypic resistance to ampicillin $(\mathrm{R}=0.5)$ and cephalothin $(\mathrm{R}=0.3)$, as well as, $b l a_{\mathrm{SHV}}$ correlated positively with the resistance to ampicillin $(\mathrm{R}=0.3)$ and cephalothin $(\mathrm{R}=0.2)$. In addition, there is positive correlation between both genes $\left(b l a_{\mathrm{TEM}}\right.$ and $\left.b l a_{\mathrm{SHV}}: 0.49\right)$.

The presence of biofilms could contribute to $Y$. enterocolitica pathogenicity; in this study, $21(70 \%)$ isolates had the capability to form biofilms. Eleven isolates were strong, six isolates were moderate, four isolates were weak biofilm producer (Figure-1), while $30 \%(9 / 30)$ were detected as non-biofilm producer. As previously mentioned, MDR was detected in 7 strains $(23.33 \%)$ of $Y$. enterocolitica isolates. By

Table-3: Number and percentage of $Y$. enterocolitica antimicrobial pattern isolated from chicken and minced meat.

\begin{tabular}{llcccccc}
\hline Antimicrobial agent & Code & \multicolumn{2}{c}{ Sensitive } & & \multicolumn{2}{c}{ Resist } \\
\cline { 3 - 4 } \cline { 7 - 8 } & & $\mathbf{n}$ & $\mathbf{\%}$ & & $\mathbf{n}$ & $\mathbf{\%}$ \\
\hline Ciprofloxacin & CIP & 24 & 80 & & 6 & 20 \\
Gentamicin & GN & 21 & 70 & & 9 & 30 \\
Cefotaxime & CTX & 19 & 63.33 & & 11 & 36.67 \\
Streptomycin & S & 15 & 50 & & 15 & 50 \\
Cephalothin & CF & 5 & 16.66 & & 25 & 83.33 \\
Ampicillin & AMP & 5 & 16.66 & & 25 & 83.33 \\
\hline
\end{tabular}

$\mathrm{CF}=$ Cephalothin, $\mathrm{AMP}=$ Ampicillin, $\mathrm{S}=$ Streptomycin, $\mathrm{CTX}=$ Cefotaxime, $\mathrm{CIP}=$ Ciprofloxacin, $\mathrm{GN}=$ Gentamicin, Y.enterocolitica $=$ Yersinia enterocolitica

Table-4: The distribution of antimicrobial resistance profiles among $Y$. enterocolitica isolates.

\begin{tabular}{lcc}
\hline $\begin{array}{l}\text { Antimicrobial } \\
\text { resistance profile }\end{array}$ & $\begin{array}{c}\text { Number of } \\
\text { antibiotics }\end{array}$ & $\begin{array}{c}\text { Number } \\
\text { of isolates }\end{array}$ \\
\hline CIP, CTX, GN, CF, AMP & 5 & 1 \\
CTX, GN, S, CF, AMP & 5 & 1 \\
CTX, S, CF, AMP & 4 & 2 \\
S, AMP, GN, CIP & 4 & 1 \\
CIP, CTX, GN, S & 4 & 1 \\
GN, S, CF, AMP & 4 & 1 \\
CTX, CF, AMP & 3 & 2 \\
GN, CF, AMP & 3 & 2 \\
CIP, CF, AMP & 3 & 1 \\
S, CF, AMP & 3 & 8 \\
GN, S, CF & 3 & 1 \\
CTX, AMP & 2 & 1 \\
CF, AMP & 2 & 5 \\
CTX, CF & 2 & 1 \\
CTX & 1 & 1 \\
CIP & 1 & 1
\end{tabular}

$\mathrm{CF}=$ Cephalothin, $\mathrm{AMP}=$ Ampicillin, $\mathrm{CTX}=$ Cefotaxime, $Y$. enterocolitica $=$ Yersinia enterocolitica 

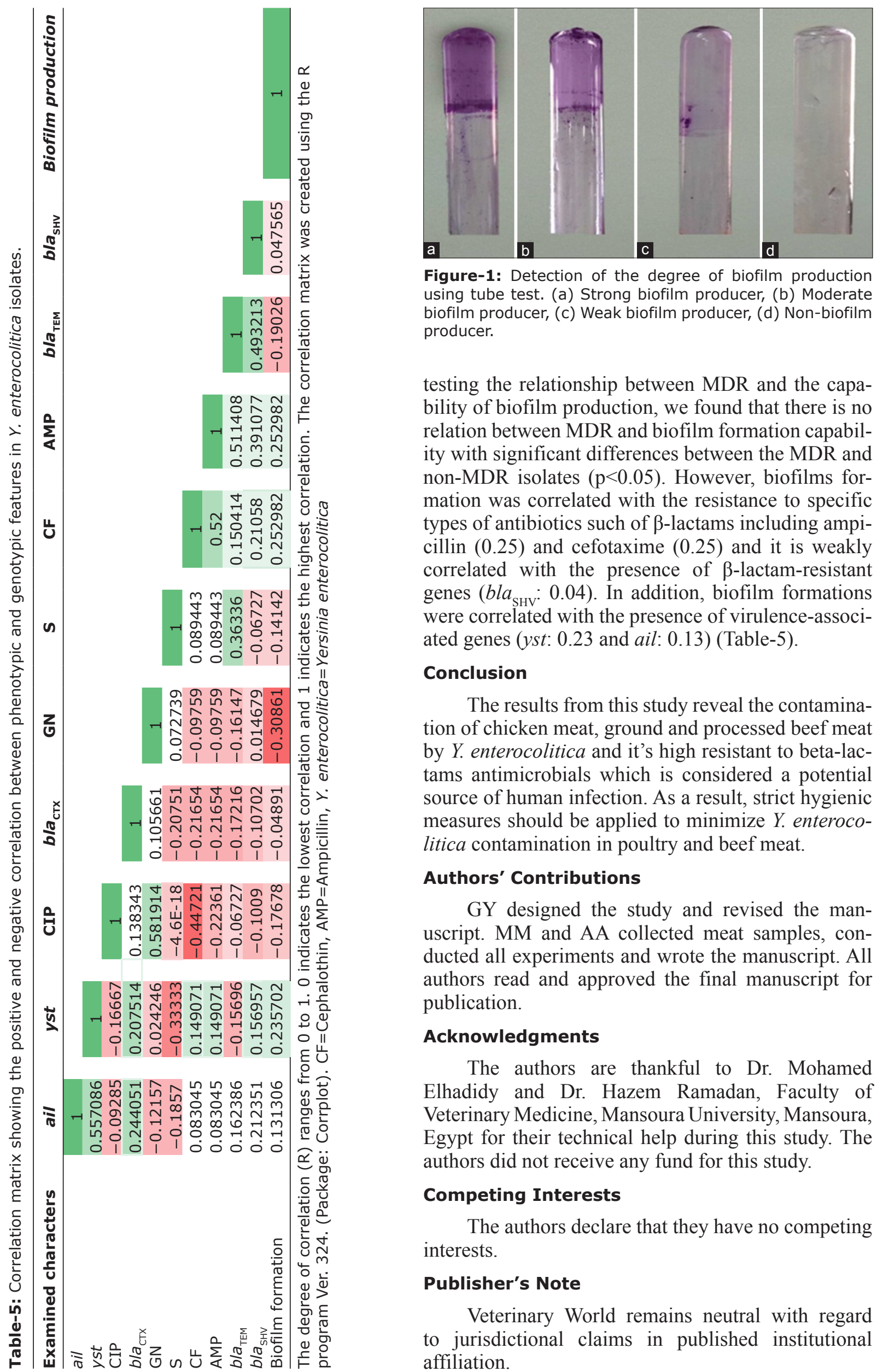

Figure-1: Detection of the degree of biofilm production using tube test. (a) Strong biofilm producer, (b) Moderate biofilm producer, (c) Weak biofilm producer, (d) Non-biofilm producer.

testing the relationship between MDR and the capability of biofilm production, we found that there is no relation between MDR and biofilm formation capability with significant differences between the MDR and non-MDR isolates $(p<0.05)$. However, biofilms formation was correlated with the resistance to specific types of antibiotics such of $\beta$-lactams including ampicillin (0.25) and cefotaxime (0.25) and it is weakly correlated with the presence of $\beta$-lactam-resistant genes $\left(b l a_{\mathrm{SHV}}: 0.04\right)$. In addition, biofilm formations were correlated with the presence of virulence-associated genes (yst: 0.23 and ail: 0.13) (Table-5).

\section{Conclusion}

The results from this study reveal the contamination of chicken meat, ground and processed beef meat by $Y$. enterocolitica and it's high resistant to beta-lactams antimicrobials which is considered a potential source of human infection. As a result, strict hygienic measures should be applied to minimize $Y$. enterocolitica contamination in poultry and beef meat.

\section{Authors' Contributions}

GY designed the study and revised the manuscript. MM and AA collected meat samples, conducted all experiments and wrote the manuscript. All authors read and approved the final manuscript for publication.

\section{Acknowledgments}

The authors are thankful to Dr. Mohamed Elhadidy and Dr. Hazem Ramadan, Faculty of Veterinary Medicine, Mansoura University, Mansoura, Egypt for their technical help during this study. The authors did not receive any fund for this study.

\section{Competing Interests} interests.

The authors declare that they have no competing

\section{Publisher's Note}

Veterinary World remains neutral with regard to jurisdictional claims in published institutional affiliation. 


\section{References}

1. Aghamohammad, S., Gholami, M., Dabiri, H., Rahimzadeh, G., Souod, N., Goudarzi, H., Sardari, S. and Mohammadzadeh, A. (2015) Distribution and antimicrobial resistance profile of Yersinia species isolated from chicken and beef meat. Int. J. Enteric Pathog., 3(4): e29009.

2. Bolton, D.J., Ivory, C. and McDowell, D. (2013) A small study of Yersinia enterocolitica in pigs from birth to carcass and characterization of porcine and human strains. Food Control, 33(2): 521-524.

3. Nesbakken, T. (2015) Update on Yersinia as a foodborne pathogen: Analysis and control. Adv. Microb. Food Saf., 2: 33-58.

4. Bonardi, S., Bruini, I. and D'Incau, M. (2016) Detection, seroprevalence and antimicrobial resistance of Yersinia enterocolitica and Yersinia pseudotuberculosis in pig tonsils in Northern Italy. Int. J. Food Microbiol., 235(October 2016): 125-32.

5. Tan, L.K., Ooi, P.T. and Thong, K.L. (2014) Prevalence of Yersinia enterocolitica from food and pigs in selected states of Malaysia. Food Control, 35(1): 94-100.

6. Anju, P., Latha, C., Sunil, B. and Sethulekshmi, C. (2014) Detection of Salmonella and Yersinia spp. In uncooked retail chicken meat in Kerala by multiplex PCR. Int. J. Curr. Microbiol. Appl. Sci., 3(6): 1028-1034.

7. Zeinali, T., Jamshidi, A., Rad, M. and Bassami, M. (2015) A comparison analysis of Listeria monocytogenes isolates recovered from chicken carcasses and human by using RAPD PCR. Int. J. Clin. Exp. Med., 8(6): 10152-10157.

8. Ryan, K.J. and Ray, C.G., editors. (2004) Sherris Medical Microbiology: An Introduction to Infectious Disease. $4^{\text {th }} \mathrm{ed}$. McGraw-Hill, New York.

9. Krajinović, V., Andrašević, A.T. and Baršić, B. (2007) Tricuspidal valve endocarditis due to Yersinia enterocolitica. Infection, 35(3): 203-205.

10. Fàbrega, A. and Vila, J. (2012) Yersinia enterocolitica: Pathogenesis, virulence and antimicrobial resistance. Enferm. Infecc. Microbiol. Clin., 30(1): 24-32.

11. Pierson, D.E. and Falkow, S. (1993) The ail gene of Yersinia enterocolitica has a role in the ability of the organism to survive serum killing. Infect. Immun., 61(5): 1846-1852.

12. Singh, I. and Virdi, J.S. (2004) Production of Yersinia stable toxin (YST) and distribution of yst genes in biotype 1A strains of Yersinia enterocolitica. J. Med. Microbiol., 53(11): 1065-1068.

13. Lupi, A., Poletti, F., Mondino, V., Canale, C., Leonardo, L., Rognoni, A. and Nardi, F. (2013) Subacute endocarditis caused by Yersinia enterocolitica: A case report. Eur. J. Clin. Microbiol. Infect. Dis., 45(4): 329-333.

14. Hall, C.W. and Mah, T.F. (2017) Molecular mechanisms of biofilm-based antibiotic resistance and tolerance in pathogenic bacteria. FEMS Microbiol. Rev., 41(3): 276-301.

15. Ioannidis, A., Kyratsa, A., Ioannidou, V., Bersimis, S. and Chatzipanagiotou, S. (2014) Detection of biofilm production of Yersinia enterocolitica strains isolated from infected children and comparative antimicrobial susceptibility of biofilm versus planktonic forms. Mol. Diagn. Ther., 18(3): 309-314.

16. Bercovier, H. and Mollaret, H.H. (1984) Genus XIV. Yersinia. In: Krieg, N.R., editor. Bergey's Manual of Systematic Bacteriology. Vol. 1. Williams and Wilkins Company, Baltimore. p 498-506.

17. Wannet, W.J., Reessink, M., Brunings, H.A. and Maas, H.M. (2001) Detection of pathogenic Yersinia enterocolitica by a rapid and sensitive duplex PCR assay. J. Clin. Microbiol., 39(12): 4483-4486.

18. Koua, A., Solange, K.N.E., Thomas, D.E.A., Germain, K.T., Mireille, D., Sébastien, A.L. and Marcellin, D.K. (2014) Characterization of Yersinia spp. Strains isolated from pigs in Abidjan, Cote d'Ivoire, West Africa. Afr. J. Microbiol. Res., 8(18): 1909-1915.
19. Belaaouaj, A., Lapoumeroulie, C., Caniça, M.M., Vedel, G.,Névot, P., Krishnamoorthy, R. and Paul, G. (1994) Nucleotide sequences of the genes coding for the TEM-like $\beta$-lactamases IRT-1 and IRT-2 (formerly called TRI- 1 and TRI-2). FEMS Microbiol. Lett., 120(1-2): 75-80.

20. Pitout, J.D.D., Thomson, K.S., Hanson, N.D., Ehrhardt, A.F., Moland, E.S. and Sanders, C.C. (1998) $\beta$-lactamases responsible for resistance to expanded-spectrum cephalosporins in Klebsiella pneumoniae, Escherichia coli, and Proteus mirabilis isolates recovered in South Africa. Antimicrob. Agents Chemother, 42(6): 1350-1355.

21. Clinical and Laboratory Standards Institute. (2015) Performance Standards for Antimicrobial Susceptibility Testing; $25^{\text {th }}$ Informational Supplement M100-S25. Clinical and Laboratory Standards Institute, Wayne.

22. Hassan, A., Usman, J., Kaleem, F., Omair, M., Khalid, A. and Iqbal, M. (2011) Evaluation of different detection methods of biofilm formation in the clinical isolates. Braz. J. Infect. Dis., 15(4): 305-311.

23. Zadernowska, A., Chajęcka-Wierzchowska, W. and Łaniewska-Trokenheim, Ł. (2013) Yersinia enterocolitica: A dangerous, but often ignored, foodborne pathogen. Food Rev. Int., 30(1): 53-70.

24. Shabana, S., Khalil, S. and Hegazy, A. (2015) Molecular characterization of Yersinia enterocolitica isolated from chicken meat samples. Alex. J. Vet. Sci., 46(1): 124-129.

25. Momtaz, H., Davood, R.M. and Safarpoor, D.F. (2013) Identification and characterization of Yersinia enterocolitica isolated from raw chicken meat based on molecular and biological techniques. J. Appl. Poult. Res., 22(1): 137-145.

26. Sirghani, K., Zeinali, T. and Jamshidi, A. (2018) Detection of Yersinia enterocolitica in retail chicken meat, Mashhad, Iran. J Pathog. 2018: Article ID 1286216.

27. Karib, H., Boussatta, H. and Seeger, H. (1999) Yersinia enterocolitica: Verkommen in rohem fleisch und fleischprodukten in Marokko. Fleischwirtsch, 74: 1332-1333.

28. Nortjé, G.L., Vorster, S.M., Greebe, R.P. and Steyn, P.L. (1999) Occurrence of Bacillus cereus and Yersinia enterocolitica is South African retail meats. Food Microbiol., 16(3): 213-217.

29. Ye, Q., Wu, Q., Hu, H., Zhang, J. and Huang, H. (2016) Prevalence and characterization of Yersinia enterocolitica isolated from retail foods in China. Food Control, 61(March 2016): 20-27.

30. Nesbakken, T., Iversen, T., Eckner, K. and Lium, B. (2006) Testing of pathogenic Yersinia enterocolitica in pig herds based on the natural dynamic of infection. Int. J. Food Microbiol., 111(2): 99-104.

31. Simonova, J., Vazlerova, M. and Steinhauserova, I. (2007) Detection of pathogenic Yersinia enterocolitica serotype O:3 by biochemical, serological, and PCR methods. Czech J. Food Sci., 25(4): 214-220.

32. Peng, Z., Zou, M., Li, M., Liu, D., Guan, W., Hao, Q., Xu, J., Zhang, S., Jing, H., Li, Y. and Liu, X. (2018) Prevalence, antimicrobial resistance and phylogenetic characterization of Yersinia enterocolitica in retail poultry meat and swine feces in parts of China. Food Control, 93(Novamber 2018): 121-128.

33. Sacchini, L., Garofolo, G., Di Serafino, G., Marotta, F., Ricci, L., Di Donato, G., Miracco, M.G., Perletta, F. and Di Giannatale, E. (2018) The prevalence, characterization, and antimicrobial resistance of Yersinia enterocolitica in pigs from Central Italy. Vet. Ital., 54(2): 115-123.

34. Bhagat, N. and Virdi, J.S. (2007) Distribution of virulence-associated genes in Yersinia enterocolitica biovar 1A correlates with clonal groups and not the source of isolation. FEMS Microbiol. Lett., 266(2): 177-183.

35. Baumgartner, A., Küffer, M., Suter, D., Jemmi, T. and Rohner, P. (2007) Antimicrobial resistance of Yersinia enterocolitica strains from human patients, pigs and retail pork in Switzerland. Int. J. Food Microbiol., 115(1): 110-114.

36. Anju, P., Latha, C., Sunil, B. and Sethulekshmi, C. (2014b) 
Antimicrobial resistance profile of Yersinia enterocolitica and Yersinia intermedia isolates from retail pork. Int. J. Curr. Microbiol. Appl. Sci., 3(8): 231-234.

37. Shanmugapriya, S., Senthilmurugan, T. and Thayumanavan, T. (2014) Genetic diversity among Yersinia enterocolitica isolated from chicken and fish in and around Coimbatore City, India. Iran. J. Public Health, 43(6): 835-844.

38. Seoane, A. and Lobo, J.M.G. (1991) Cloning of chromosomal $\beta$-lactamase genes from Yersinia enterocolitica. J. Gen. Microbiol., 137(1): 141-146.

$* * * * * * * *$ 